\title{
How Iranian men perceive sexual and reproductive health? A qualitative study
}

\section{Razieh Lotfi}

Alborz University of Medical Sciences

Seyed Ali Azin

Institute for Health Sciences Research

Effat Hatefnia

Alborz University of Medical Sciences

Mina Amiri

Research Institute for Endocrine Sciences

Masoumeh Simbar

Research Institute for Endocrine Sciences

Fahimeh Ramezani Tehrani ( $\sim$ ramezani@endocrine.ac.ir)

Research Institute for Endocrine Sciences

\section{Research}

Keywords: Sexual/ reproductive health, men, qualitative study

Posted Date: December 20th, 2019

DOI: https://doi.org/10.21203/rs.2.19398/v1

License: (c) (i) This work is licensed under a Creative Commons Attribution 4.0 International License.

Read Full License 


\section{Abstract}

Background Despite the effective role of men in promoting their sexual and reproductive health, they have been often been overlooked for cultural and social issues and limited data are available in this context. In developing countries, the majority of men have limited knowledge and ability in terms of reproductive and sexual health. Hence, this study aimed to investigate male perceptions of sexual and reproductive health concepts.

Materials and methods Using the conventional content analysis approach, a qualitative study was conducted on data retrieved through semi-structured interviews with 19 adult males aged 18 to 59 years, purposefully selected from among populations of health centers in the province of Alborz, Iran.

Results Three main concepts and 9 categories emerged from the conventional content analysis: 1) Needs including "access to sexual and reproductive health services", "awareness", and "high-quality and safe sex"; 2) Responsibilities including "health- seeking behaviors", "sexual skills", "childbearing responsibilities" and "ethical commitment"; and 3) Social norms including "gender role attitudes", and "changing marriage rules".

Conclusion This study showed that structural factors along with cultural and social norms affect sexual and reproductive health in men, who are men not adequately taken care and many of their sexual and reproductive health needs have not yet been addressed. Participants believed that men are responsible for their sexual reproductive health, although they have often difficulties fulfilling their responsibilities because of inadequate knowledge on the subject and the lack of access to sexual/ reproductive health services. Hence, along with socioeconomic changes, the health care system should be prepared to meet these needs and responsibilities using preventive strategies and programs.

\section{Plain English Summary}

Despite the effective role of men in promoting their sexual and reproductive health, they have been often been overlooked for cultural and social issues and limited data are available in this context. In developing countries, the majority of men have limited knowledge and ability in terms of reproductive and sexual health. Hence, we investigated male perceptions of sexual and reproductive health concepts.

Using the conventional content analysis approach, a qualitative study was conducted on data retrieved through semi-structured interviews with 19 adult males aged 18 to 59 years, purposefully selected from among populations of health centers.

Three main concepts and 9 categories emerged from the conventional content analysis: 1) Needs including "access to sexual and reproductive health services", "awareness", and "high-quality and safe sex"; 2) Responsibilities including "health- seeking behaviors", "sexual skills", "childbearing responsibilities" and "ethical commitment"; and 3) Social norms including "gender role attitudes", and "changing marriage rules". 
In conclusion, structural factors along with cultural and social norms affect sexual and reproductive health in men, who are men not adequately taken care and many of their sexual and reproductive health needs have not yet been addressed. Participants believed that men are responsible for their sexual reproductive health, although they have often difficulties fulfilling their responsibilities because of inadequate knowledge on the subject and the lack of access to sexual/ reproductive health services. Hence, along with socioeconomic changes, the health care system should be prepared to meet these needs and responsibilities using preventive strategies and programs.

\section{Introduction}

Men's sexual and reproductive health is one of the major components of their general health [1]. Despite the effective role of men in promoting their sexual and reproductive health, they have been often neglected for cultural and social causes and limited researches have been conducted in this context [2]. By the mid-1990 s, in most countries, policies on sexual and reproductive health such as family planning, sexually transmitted infections, sexual health focused on women to promote their health through increased awareness on the issues [3].

Iran has a female-oriented health system, in which men often have limited awareness on their sexual and reproductive health needs and responsibilities [4]. However, evidence shows that should the responsibility for sexual and reproductive health services be reserved exclusively for women, half of the effective population i.e. men, will be excluded from the field of sexual and reproductive health. In such a situation, marginalizing and neglecting men's health needs would make it impossible for them to achieve sexual and reproductive health goals [5].

Men's participation is considered an important strategy to promote sexual and reproductive health not only for men but also in women [6, 7]. Considering the social and cultural conditions of developing countries, the key roles of men in reproductive health issues can be outlined with three approaches: 1 ) Emphasizing on unmet needs of men for their sexual and reproductive health, 2) being able emotionally supporting women to improve access to health services, 3) Men plying an effective roles for positive changes [3]. Men are often as known as the head of household and for their leadership in the community because of their provider, and their policy and decision making. Many gender roles that place women second to men, thereby influencing people's beliefs, attitudes and practices, not only endangering women's health but also the health of their male counterparts [8].

In developing countries, many men do not always have sufficient knowledge and ability in terms of sexual and reproductive health [9]; nowadays, certain sexual and reproductive health issues for them such as attitudes toward gender roles, responsibilities in healthy sexual relationships and childbearing, prevention of sexually transmitted infections such as human immunodeficiency virus (HIV), and screening behaviors for the prevention of cancers are important $[3,10-12]$. Studies conducted on the sexual and reproductive health needs of men show that, despite efforts to improve male reproductive health, they lack adequate knowledge on their reproductive health, due to which their sexual health has 
declined in recent years $[13,14]$. Hence, it is essential that health services to provide the necessary support to enhance the sexual and reproductive health knowledge of men [15].

It is well known that qualitative studies can clarify the viewpoints of men on sexual issues, gender roles, inclination to participate in prevention programs of sexually transmitted diseases and cancers and their performance in terms of accountability and reproductive health issues. Hence, this qualitative study aimed to investigate male perceptions of sexual and reproductive health concepts. Our study findings can be used to design interventions and programs for the promotion of male sexual and reproductive health.

\section{Material And Methods}

\section{Participants and data collection}

Using a conventional content analysis approach, a qualitative study was conducted on data acquired through semi-structured interviews with 19 adult males, aged 18 to 59 years, selected from the population of health centers in the province of Alborz, Iran from May 2016 to April 2017. In addition, some participants included, were from private health centers, parks, and clubs, as needed. According to the nature of qualitative research, access centers for these individuals can be diverse. Individuals were selected purposefully, with much variation in terms of age, education, occupation, income, and marital status; individual interviews were continued until saturation. In qualitative research, it is better to select the first participant to provide comprehensive and valuable information [16]. Hence, in this study, after initial evaluations, the first participant was a knowledgeable person who was skilled in expression and sexual health experience. There was access to the participants via two channels: First, one of the health care providers selected qualified male participants by communicating with them; then, the researcher invited these individuals to participate in interviews after explaining the goals of the study.

\section{Ethical Considerations}

This research project was approved by the ethics committee of Alborz University of medical sciences (code: Abzums.rec.1394.107). Written informed consent to participate and to permit the tape recording of interviews was obtained from all participants, who were assured that audio files would be kept confidential in a safe place. All participants were free to withdraw at any time from the study. Interviews were conducted in separate quiet settings.

\section{Data Analysis}

A conventional content analysis approach was used to analyze the data, which was carried out simultaneously using the constant comparative method; this method as an inductive qualitative data analysis strategy combines "inductive category coding with a comparison of the social incidents observed and coded" [17].

The interviews were recorded on tapes, and recorded interviews were subsequently transcribed verbatim and read several times to reach an overall understanding of each participant's perspective on sexual and 
reproductive health; first, each participant's interview was analyzed and then the next interview was conducted. All texts were divided into meaning units (each one containing several words, sentences, and phrases) related to our study aim; the meaning units were condensed into open coding $[18,19]$. Next, our data was organized and the condensed meaning units were abstracted with codes. Finally, codes were arranged into subcategories and categories, based on assessment of their similarities and differences [18]. OneNote software was used to classify the codes and continue the data analysis.

\section{Rigor}

To evaluate the rigor and confirm the trustworthiness of the qualitative data, we used the Lincoln and Guba's [17] criteria including credibility, dependability, transferability, and confirmability. Credibility, i.e. means the confidence one can have in the findings, can be maintained by some strategies such as, prolonged engagement, peer debriefing, and member checking. In this study, member checking, an important step in protecting against researcher bias, allowed the five randomly selected men the opportunity to either agree or disagree with the interpretations extracted from the interviews; they were given a full transcript of coded interviews with a summary of the emergent themes to assess whether the codes matched their viewpoints [20]. The participants confirmed and documented their agreement with the concepts that had been developed by researchers.

Debriefing, another step towards confirming trustworthiness [17] was established by sharing the data and ongoing analysis with two senior experts in qualitative research; during analysis, the research team worked together, participating in meetings to discuss emergent codes and themes and any revisions if necessary; dependability and confirmability were accomplished using an audit trail. In order to ensure data accuracy, the researchers kept decision trails to document the decisions that were made over the course of the study. In order to assess the reliability of the data, independent coding was done by two authors and the concordance was calculated to be highly acceptable at $90 \%$.

\section{Results}

In this study 19 interviews were conducted with 19 adult males, aged $18-59$ (mean age 37.4 years). The participants were representative of a local population with good diversity of various demographic characteristics. Table 1 shows the demographic characteristics of study participants.

Three main concepts and 9 categories emerged from the conventional content analysis: 1) Needs including "access to sexual and reproductive health services", "awareness", and "high-quality and safe sex"; 2) Responsibilities including "health - seeking behaviors", "sexual skills", "childbearing responsibilities" and "ethical commitment"; and 3) Social norms including "gender role attitudes", and "changing marriage rules" (Table 2)

\section{1 - Needs}


The concept of needs has three categories including access to sexual and reproductive health services, awareness, and high-quality and safe sex.

\section{1-1 - Access to sexual and reproductive health services}

Most men did not know where to refer if they needed specialized services on sexual and reproductive health issues. Access to sexual and reproductive health services has two sub-categories including sexual and reproductive health service delivery centers and supportive environments.

\section{1-1-1 - Centers for sexual and reproductive health service delivery}

Most men expressed their personal experiences to highlight their difficulties for access to their services required in the fields of prevention and treatment of infections, sexual problems, and infertility. Even educated participants in medical fields believed that they needed to learn more about sexual and reproductive health issues.

"I think that sexuality is a real need. Men have often inadequate information on sexual health services. Even, although I am a Master of Sciences in Health, I do not have enough information about sexual issues. Therefore, special centers should be considered to provide health services for men". (36 years old, single, MSc)

\section{1-1-2 - Supportive environment}

Some participants suggested that creating a safe and supportive environment to meet men's sexual needs is vital to prevent sexual chaos in society, mainly due to the current conditions of society, in which marriage requirements are not met and the age of marriage has increased.

"I think that it's very good to limit sex, e.g. it can be limited to a permanent specified location, a place which can be used to meet sexual needs; having such a place will ensure safety for men and women". (50 years old, single, diploma)

\section{1-2 - Awareness}

Study participants believed that the awareness about male genital tract symptoms, timely diagnosis methods, prevention of diseases, cancers, and sexually transmitted infections and HIV, infertility and sexual issues are important factors for adopting sexual and reproductive health behaviors. Subcategories of awareness include sexually transmitted infection (STIs)/ HIV/ acquired immunodeficiency syndrome (AIDS), cancers, infertility, sexual.

\section{1-2-1 - Sexual issues}

Men believed that if they have higher awareness, their sexual health would also improve. 
"If I had enough sex awareness, I would prefer my wife to be prepared for enjoyable experiences during sex. I wish I had more knowledge sexual issues". (31 years old, married, bachelor's degree)

There were major misconceptions about the signs of diseases and the sexual and reproductive disorders in men. An interviewee considered occasional and spontaneous ejaculation at bedtime as a disorder; he thought that masturbating is a factor in inducing weakness of the body, and even a source of unemployment and dismissal from a job.

"I think that erection during sleep and masturbation cause my weakness, frailty, anger, and even the loss of my job". (25 years old, single, guidance school)

\section{1-2-2 - STIs/ HIV/AIDS}

"As far as I know, AIDS is transmitted through dirty work. I think that I do not get AIDS by once sex; but I'm not sure. I wish I knew what to do". (25 years old, single, guidance school)

\section{1-2-3 - Male genital cancers and infertility}

Male information on male genital cancers and infertility was inadequate; this can influence their exploratory behaviors.

"I do not really have any information about male genital disorders. I just know that the testis is a fertility organ in men. Nobody gives us comprehensive information about the genital system and its diseases". (50 years old, single, diploma)

\section{1-3 - High-quality and safe sex}

Majority of men considered high-quality and safe sex very important issues and a positive sign of sexual health.

\section{1-3-1 - Sexual pleasure}

Among sexual health issues, sexual pleasure was the main topic of discussions which most men had in terms of sexual health. Most men considered positive satisfactory feelings of both partners as the criterion for sexual health.

"In my opinion, the quality of the relationship between the two sex partners is very important. I think that if both sex partners adequately enjoy sex, it means they have been successful in their sexual relationships". (27 years old, married, bachelor degree)

\section{1-3-2 - Sexual satisfaction}

The majority of men, while expressing the importance of sexual satisfaction in couples' health, referred to strategies that increased satisfaction, while others believed that a lack of sexual satisfaction can lead to being unfaithful in their relationships. 
"I think that because sexual issues are so important for people, sexual dissatisfaction leads to being unfaithful in their relationships". (24 years old, single, associate degree)

\section{1-3-3 - Safety of sex}

The concept of safety in the quality of sexual relationships was repeatedly discussed in the participants' conversations of the study. From the point of view of participants, safety includes the need to have a suitable companion for good sex, elimination of stress and tensions to be able to have good mutual relationship without thinking about others, and feeling empowered.

"In terms of health, if these are marital relationships, we are more relaxed and not worried about future problems". (28 years old, married, bachelor degree)

\section{1-3-4 - Sexual function}

Most participants emphasized the need to maintain an appropriate sexual relations for the survival of married life and quality of sex; they also had different perspectives on premature ejaculation, which was one of the most commonly considered issues among participants in the study.

\section{2 - Responsibilities}

This concept includes health-seeking behaviors, sexual skills, childbearing responsibilities, and ethical commitment.

\section{2-1 - Health- seeking behaviors}

Participants believed that men had checkups for their health status only when they or their friends/ their relatives had a specific disease. Some men were afraid to talk about their fertility and sexual problems and tried to hide it.

\section{2-1-1 - Regular check up}

Almost no participant had ever referred to a health care provider for issues related to his reproductive and sexual system before the problem occurred.

"I do not have enough information on essential checkups related to fertility and sexual health. For example, the only information I have on the prostate is because my uncle died due to prostate cancer; I went for a checkup, but they told me to have tests after the age of 40 years." (32 years old, single, diploma)

\section{2-1-2 - Fear and hiding the problems}


Most participants had a fear of problems with the reproductive and sexual system, and other participants believed that these problems or infertility caused serious concern.

"I would like to see a doctor and be tested for evaluating my fertility, but l'm afraid the results show that I'm infertile. For this reason, I do not refer to the doctor to check my fertility status." (24 years old, single, associate degree)

\section{2-2 - Sexual skills}

Participants believed that for sexual success, which is a prerequisite for the continuation of marital life, and is the cornerstone of a good marital relationship; sexual skills should be associated with mutual satisfaction.

\section{2-2-1 - Sexual negotiation}

From the perspective of men, negotiation skills about sexual needs were necessary for self-confidence in sexual issues; they believed that these skills can manage sexual problems.

"I think that negotiation is one of the most important skills among couples. For example, when two people talk, they can discuss their own issues, and problems are much easier to solve. Negotiation can help to discover solutions and couples also learn to understand what their partner enjoys." (31 years old, married, MSc)

\section{2-2-2 - Interactive and respectable sex practice}

This subcategory includes women's psychological readiness and satisfaction of virgins for a sexual relationship; this readiness is very important, and is considered as an ethical issue.

"I think sexual issues must be respected during sexual relationships, e.g., it is important that whether my behavior in this position is acceptable to my partner; did I consider all ethical issues during sexual relationships?" (27 years old, married, bachelor degree)

\section{2-2-3 - Sexually protective behavior}

Although all men were familiar with the condom, they sometimes were reluctant to use it even in high-risk conditions, or they did not have the skill of convincing their partner to agree to its use. We asked participants the following question:

If the sex worker wants you to have a relationship without using a condom, what is your reaction? One of the participants hesitantly answered I use a condom.

"I think that if I tell my sexual partner that I want to use a condom, my partner will be upset by my demand. One of my friends suggested that in such cases, I tell my partner, that I am ill. But, in my opinion, this way is ineffective and my partner will get annoyed."(26 years old, single, Associate Degree) 


\section{2-3 - Childbearing responsibilities}

Study participants believed that a responsible man should consider some issues such as financing, parental maturity, parenting skills, and family planning before childbearing.

\section{2-3-1 - Financing and providing children's welfare}

Participants of the study had different perspectives on the relationship between childbearing and financial and social welfare; however, the majority of men believed that they should have appropriate conditions for childbearing.

"In our society, economic issues are major problems that force people to have only one child, or not have any children." (36 years old, single, MSc)

\section{2-3-2 - Parents' emotional maturity and skill}

Some participants believed that men should accept the responsibility for childbearing, only when they reach achieve emotional maturity for adapting to difficulties of admitting a third child in their lives.

"In today's society, economic and psychological problems are highly prevalent, whereas many people cannot even manage their own personal lives. In my opinion, egocentrism and selfishness make people unable to reach parental maturity, and make them think negatively about bringing up children and childrearing." (33 years old, married, MSc)

\section{2-3-3 - Family planning}

From the perspective of all participants, family planning was a shared responsibility for women and men. In this respect, some participants believed that men sometimes have the major responsibility.

"In my opinion, although both men and women are responsible for unwanted pregnancy prevention, more responsibility is with men." (27 years old, married, bachelor degree)

\section{2-4 - Ethical commitment}

All men in this study believed that ethical commitment and adherence to morality are essential to maintain marital relationships and child-rearing; they also said that the lack of maintaining marital relationships was common in the community.

\section{2-4-1 - Marital and Extramarital relationships}

"When a man marries, he is committed to his family (wife and child). In my opinion, the concept of commitment applies for different issues. In other words, we should be committed to all issues of life. I know a lot of people who, despite being married, are not committed to their marital relationship and they have sex with others." (24 years old, single, associate degree) 


\section{2-4-2 - Child upbringing}

One participant described his efforts to avoid having an extramarital relationship and also providing a suitable behavioral pattern for his or her child as follows:

"In many cases, I have been denied by my relatives; for example, if someone drinks alcohol, I will not associated with him at all, even if the person is my father. Someone who does an unpleasant act, I'll cut off all contact with him/her"(49 years old, married, bachelor degree)

\section{3 - Social norms}

This concept includes gender role attitudes and changing marriage rules.

\section{3-1 - Gender role attitudes}

This category describes gender role attitudes in the fields of fertility and infertility and sexual relationships. Study results show a change in attitudes of men from traditional attitudes to modern.

\section{3-1-1 - Fertility and infertility}

Despite many men explicitly stating the importance of having a child in their life, some believed that having a good life in a situation where fertility was not possible for couples is important. From the perspective of men of the study, both parents should be involved in making decisions about having children.

\section{3-1-2 - Sexual relationships}

Participants focused on the rights and needs of women/spouses in sexual intercourse; they believed that both, the woman and the man should enjoy sex, otherwise it would be selfish and could cause infidelity.

"I believed that not only should I be satisfied; both the man and the women have the right to enjoy sex and reach orgasm. I think that having sex without enjoying a sexual partner is like doing business. In the past years, there was absolute manhood, but today, each partner expects everything to be good in sex. If sex is not performed in accordance with the partner's wishes, she may be unfaithful him." (26 years old, single, bachelor degree)

Some men said that having sex before marriage in the woman can lead to lack of trust toward her.

"I think that if a woman/ man tells her/his spouse about having a history of sex before marriage with another, the spouse thinks she may still have sex with other people." (50 years old, single, guidance school) 
Some men tried to think like women; these individuals did not accept the plurality of sexual partners in relationships.

\section{3-2 - Changing marriage rules}

This category includes white marriage and suspicion towards non-virgin girls.

\section{3-2-1 - White marriage}

Today, many Iranians cohabit before marriage as white marriage. From the perspective of younger and more educated participants, white marriage is inevitable and growing among young couples. Some men believed that white marriage was a prerequisite for marriage. They wanted to marry after ensuring that they were sexually compatible.

"My wife and I lived together in a house before getting married. Many people do this, and in my opinion, it is okay." (28 years old, married, Ph.D.)

\section{3-2-2 - Suspicion towards non-virgin girls}

Most men did not trust the girls who have had sexual relationships with other men before marriage and believed that such girls are unsuitable for marriage. For some men, the virginity issue is an important criterion for choosing a spouse.

"In my opinion, a girl who has sex with me, has probably been in a relationship with other men and is not trustworthy for a marital relationship. Although some men who know that a girl previously had sex with others, they marry her; I believe that their relationships are often temporary." (33 years old, married, diploma)

\section{Discussion}

This study is the first to investigate views of Iranian in terms of sexual and reproductive health, using the qualitative approach. Studies on the impact of gender on sexual and reproductive behaviors have more focused more on women, which can lead to half of the population (men) being overlooked; indeed, their views on fertility and sexual health, their sexual behavior and, consequently, the spread of infections such as HIV / AIDS, cancers and other diseases are not considered. In addition to the lack of research in this field, sexual and reproductive health services are not often available, and men have difficulty receiving these services [21].

In this study, from the perspective of Iranian men, sexual and reproductive health is described in terms of three concepts of needs, responsibilities, and social norms affecting these aspects of their health; majority of men report difficulties in accessing related health service centers and increasing their awareness in this area. Although there are no accurate estimates on the utilization of sexual and reproductive health services in Iran, evidence suggests that access to sexual and reproductive health 
services and utilization of these services in the country is limited [22]; therefore, the sexual and reproductive needs of men, especially younger men, rank higher than other health-related needs [23]. Despite basic steps measures taken in recent years to promote men's health, control risk factors, and prevent cardiovascular disease, no specific program are available encouraging their participation in sexual and reproductive health education programs. Since sexual issues in the Middle East and North Africa (MENA), including Iran, are often taboo, health care providers lack adequate knowledge and skills to provide the sexual services needed [1]. Hence, it seems that raising awareness and knowledge of the health team to increase the participation of men and the use of services provided should be prioritized.

Men's concern about their needs to promote their sexual and reproductive health as emphasized in this study has been also reported by other studies [24]. Collyer et al. showed that although general practitioners talk with patients about the signs and symptoms of sexually transmitted infections, they often have difficulties discussing sexual issues; they believe that men should be more responsible in their sexual health issues [25]. Previous studies demonstrated that if men's health is neglected, they may have different sexual and reproductive behaviors, based on the type of information that they obtain from different sources [26].

Most men do not refer to a doctor if they have problems with their sexual and reproductive system. Other studies also show that men in all age groups are much more likely to be exposed to health risk factors than women, while they are less likely than women to receive preventive programs and services. In addition, approximately $27 \%$ of Iranian men report having a history of infection, which is one of the most important causes of male infertility [27]. One of the concerns of men in this study was infertility. Considering the importance of childbearing for Iranian men, they tended to consult doctor to evaluate their fertility status. Male infertility rates are dramatically rising and environmental factors play an important role in its pathogenesis [28]. Hence, using strategies and designing preventive programs for infertility and its related treatments is one of the necessary and essential measures needed for male reproductive health [29].

From the perspective of men of the study, extramarital sexual relationships are one of the common problems of society, and can be problematic if they are accompanied by high-risk behaviors such as not using condoms. Iran has a "concentrated epidemic", the largest epidemic of HIV in the Middle East [30]. Although the incidence of HIV in three key populations (injection drug users, sex workers and prisoners) has declined, because of the excessive spread of HIV/AIDS through sexual transmission, it is still considered a critical risk factor for sexual and reproductive health [31]. Approximately half of HIV / AIDS transmission is due to sexual transmission, and unfortunately men's awareness on preventing HIV / AIDS is still very inadequate. According to the National AIDS Committee of the Iranian Ministry of Health (2015), only $11.7 \%$ of young people responded to questions about awareness and prevention of HIV [31]. However, according to the Ministry of Health in 2015, there is no accurate information on male sex workers in Iran, and about $61 \%$ of female sex workers used a condom in their last relationship with their client [31]. Qualitative study findings show that most males do not seek to resolve their sexual issues using a suitable approach; in addition, they lack the awareness needed to receive timely services and 
participate in sexual and reproductive health programs. Moreover, men play an important and predominant role in preventive behaviors of HIV and other sexually transmitted infections. Hence, it is critical to attend to the unmet needs of men's reproductive and sexual health by designing comprehensive programs, gender-sensitive and culture-based interventions.

In the United States, only $48 \%$ of men used sexual and reproductive health service for one year; the most common examination was the testicles assessment, and fifty percent received no other reproductive and sexual health services. These results showed that the unmet needs of men who had high-risk behaviors ranged between $32 \%$ and 63\% [32]. Findings from the Kahn et al. study (2017) conducted on American Indian and Alaska Native men, who used sexual health services showed that men with higher levels of education and income had more access to private insurance and STDs or HIV clinics. In general, men who used other health care services were more likely to benefit from these sexual health services [33].

In this study, men acknowledged that the ability of their spouses to receive services and timely visits to screening and check-ups was far more than theirs. Given that the challenges of sexual and reproductive health, including sexual disorders, sexually transmitted infections such as HIV / AIDS, and cancers can have a negative impact on marital relationships, in addition to the health of men, empowering family physicians and religious leaders in the fields of sexual and reproductive issues can reduce the problems in this area [34].

From the perspective of almost all men of the study, childbearing responsibilities and participation in family planning programs are the duty of both men and their spouses. Although Iranian men face difficulties in achieving these abilities and adapting to their family role as a father, in many countries in the MENA region, participation in sexual and reproductive health activities is still limited $(10,30)$. Participation of men in prenatal care is one of the main strategies for promoting the health of men and women.

A main strength of the study is that participants were purposefully selected, with maximum diversity, from the province of Alborz, often is called "small Iran" because of its ethnic diversity. However, like other qualitative studies, the generalizability of our findings to other populations may be limited. The selection of an experienced male interviewer for quality interviews, on sexual issues is another strength of this study. However, the unwillingness of participants to express sensitive sexual and reproductive issues could also affect the study results; the researchers have nevertheless tried to reduce this limitation by establishing a friendly and trusting relationship, especially during a qualitative interview.

\section{Conclusion}

Study results show that men are inadequately provided for and many of their sexual and reproductive health needs have not yet been addressed. Study participants believed that men are responsible for their sexual reproductive health, although they have often difficulties to fulfill their responsibilities because of inadequate access to sexual and reproductive health services. In addition, structural factors and cultural and social norms affect the sexual and reproductive health in these men. Hence, along with 
socioeconomic changes, the health care system must take the necessary steps to meet these needs and responsibilities using preventive strategies and programs.

\section{Abbreviations}

HIV:Human immunodeficiency virus; STIs:sexually transmitted infections; AIDS:acquired immunodeficiency syndrome

\section{Declarations}

\section{Ethics approval and consent to participate}

This study was approved by the ethics committee of the Alborz University of medical sciences and a written informed consent was obtained from all subjects before initiation of the study.

\section{Consent for publication}

Not applicable.

\section{Availability of data and materials}

The data used during the current study are available from the corresponding author on reasonable request.

\section{Competing interests}

The authors have no conflict of interest to declare.

\section{Funding}

None.

\section{Authors' contribution}

R.L. and F.R.T. were involved in study design, interpretation of finding, manuscript drafting, critical discussion, and revising manuscript. S.A.A. and M.S. were involved in study design, executing the study, and manuscript drafting. E.H. contributed in executing the study, and manuscript drafting. M.A. contributed in interpretation of findings, manuscript drafting, critical discussion, and revising manuscript. All authors read and approved the final manuscript.

\section{Acknowledgments}

Authors wish to acknowledge Ms Niloofar Shiva for critical editing of English grammar and syntax of the manuscript. 


\section{References}

1. Amoo EO, Oni GA, Ajayi MP, Idowu AE, Fadayomi TO, Omideyi AK: Are Men's Reproductive Health Problems and Sexual Behavior Predictors of Welfare? Am J Mens Health 2017 May;11(3):487-497 doi: 101177/1557988315598832 Epub 2015 Jul 312017.

2. Levine H, Mohri H, Ekbom A, Ramos L, Parker G, Roldan E, Jovine L, Koelle S, Lindstrand A, Immler S, et al: Male reproductive health statement (XIIth international symposium on Spermatology, may 9th12th 2018, Stockholm, Sweden. Basic Clin Androl 2018 Oct 29;28:13 doi: 101186/s12610-018-0077-z eCollection 2018.

3. Singh $D$, Lample $M$, Earnest $J$ : The involvement of men in maternal health care: cross-sectional, pilot case studies from Maligita and Kibibi, Uganda. Reprod Health 5;11:68 doi: 101186/1742-4755-11-68 2014.

4. Rahimi-Naghani S, Merghati-Khoei E, Shahbazi M, Khalajabadi Farahani F, Motamedi M, Salehi M, Karimi M, Hajebi A: Sexual and Reproductive Health Knowledge Among Men and Women Aged 15 to 49 Years in Metropolitan Tehran. J Sex Res 2016 Nov-Dec;53(9):1153-1164 doi:

101080/0022449920161148110 Epub 2016 Apr 14.

5. Greene M, Mehta M, Pulerwitz J, Wulf D, Bankole A, Singh S: Involving Men in Reproductive Health: Contributions to Development.Background paper to the report Public Choices, Private Decisions: Sexual and Reproductive Health and the Millennium Development Goals.Retrieved from www.unmillenniumproject.org/documents/Greene_et_al-final.pdf. Access date: 15 May 2015. 2009.

6. Ani F, Abiodun O, Sotunsa J, Faturoti O, Imaralu J, Olaleye A: Demographic factors related to male involvement in reproductive health care services in Nigeria. Eur J Contracept Reprod Health Care 2016;21(1):57-67 doi: 103109/1362518720151036856 Epub 2015 Apr 152016.

7. Sternberg P, Hubley J: Evaluating men's involvement as a strategy in sexual and reproductive health promotion. Health Promot Int 2004 Sep;19(3):389-96.

8. Cubbins LA, Jordan LP, Nsimba SED: Tanzanian men's gender attitudes, HIV knowledge, and risk behaviours. Etude de la population africaine $=$ African population studies, 28:1171-1181.

9. Shorey S, Ang L: Experiences, needs, and perceptions of paternal involvement during the first year after their infantsâ $€^{\mathrm{m}}$ birth: A meta-synthesis. PLoS One 2019 Jan 7;14(1): doi:101371/journalpone0210388.

10. Aguiar C, Jennings L: Impact of Male Partner Antenatal Accompaniment on Perinatal Health Outcomes in Developing Countries: A Systematic Literature Review. Matern Child Health J 2015 Feb 6.

11. Rosser JI, Zakaras JM, Hamisi S, Huchko MJ: Men's knowledge and attitudes about cervical cancer screening in Kenya. BMC Womens Health 2014 Nov 22;14:138 doi: 101186/s12905-014-0138-1.

12. Lotfi R, Tehrani FR, Yaghmaei F, Hajizadeh E: Barriers to condom use among women at risk of HIV/AIDS: a qualitative study from Iran. BMC women's health 2012, 12:13. 
13. Hajizadeh M, Javadnoori M, Javadifar N: Educational Needs of Adult Men regarding Sexual and Reproductive Health in Ahvaz, Iran. Journal of Midwifery and Reproductive Health 2015, 3 384-392.

14. Damari B, Tabrizchi N, Riazi-Isfahani S: Designing a national plan for improving sexual health in Iran: An experience of an Islamic country. Medical journal of the Islamic Republic of Iran 2016, 30:407407.

15. Sharma $S, K c B$, Khatri A: Factors influencing male participation in reproductive health: a qualitative study. J Multidiscip Healthc 2018 Oct 23;11:601-608 doi: 102147/JMDHS176267 eCollection 2018.

16. Corbin J, Strauss A: Basics of Qualitative Research: Techniques and Procedures for Developing grounded Theory (3rd ed.) Thousand Oaks, CA: Sage.; 2007.

17. Lincoln Y, Guba E: Naturalistic Inquiry. Newbury Park, CA: Sage publication; 1985.

18. Graneheim UH, Lundman B: Qualitative content analysis in nursing research: concepts, procedures and measures to achieve trustworthiness. Nurse education today 2004, 24:105-112.

19. Berg A, Kisthinios M: Are supervisors using theoretical perspectives in their work? A descriptive survey among Swedish-approved clinical supervisors. Journal of Nursing Management 2007, 15:853-861.

20. Strauss A, Corbin J: Basics of qualitative research: Techniques and procedures for developing grounded theory (2nd ed.). Thousand Oaks, CA: Sage Publications; 1998.

21. Shakour M, Salehi K, Yamany N: Reproductive Health Needs Assessment in the View of Iranian Elderly Women and Elderly Men. J Family Reprod Health 2018 Mar;12(1):34-41 2018.

22. Javadnoori M, Hajizadeh M, Javadifar N, Haghighizadeh MH: Sexual and reproductive healthcare needs of Iranian men: A cross-sectional study. International Journal of Reproductive BioMedicine 2018, 16:757-766.

23. Zare E, Simbar M, Shahhosseini Z, Alavi Majd H: The Priorities of Iranian Male Adolescents Health Needs. American Journal of Men's Health 2017, 11:1255-1259.

24. Terzioglu F, Kok G, Guvenc G, Ozdemir F, Gonenc IM, Hicyilmaz BD, Sezer NY: Sexual and Reproductive Health Education Needs, Gender Roles Attitudes and Acceptance of Couple Violence According to Engaged Men and Women. Community Ment Health J 2018, 54:354-360.

25. Collyer A, Bourke S, Temple-Smith M: Promoting sexual health to young men. Australian Journal for General Practitioners 2018, 47:376-381.

26. Bleakley A, Khurana A, Hennessy M, Ellithorpe M: How Patterns of Learning About Sexual Information Among Adolescents Are Related to Sexual Behaviors. Perspectives on Sexual and Reproductive Health 2018, 50:15-23.

27. Hosseini S-J, Abdoli M: Men's Health Project. In $3^{\text {rd }}$ Congress on men's Health, Male Infertility and Common Cancers; Feb 20, 2019; Tehran, Iran.http://www.irhrc2018.ir/pages/38/congress 10.

28. Ma Y, He X, Qi K, Wang T, Qi Y, Cui L, Wang F, Song M: Effects of environmental contaminants on fertility and reproductive health. J Environ Sci (China) 2019 Mar;77:210-217 doi:

101016/jjes201807015 Epub 2018 Aug 22. 
29. Barratt CLR, De Jonge CJ, Sharpe RM: "Man Up": the importance and strategy for placing male reproductive health centre stage in the political and research agenda. Human Reproduction 2018, 33:541-545.

30. Gokengin D, Doroudi F, Tohme J, Collins B, Madani N: HIV/AIDS: trends in the Middle East and North Africa region. Int J Infect Dis 2016 Mar;44:66-73 doi: 101016/jijid201511008.

31. Ministry of Health and Medical Education, National AIDS Committee Secretariat. Islamic Republic of Iran AIDS Progress Report On Monitoring of the United Nations General Assembly Special Session on HIV and AIDS. accessed at: http://www.unaids.org/en/regionscountries/countries/islamicrepublicofiran. 2015.

32. Kalmuss D, Tatum C: Patterns of Men's Use of Sexual and Reproductive Health Services. Perspectives on Sexual and Reproductive Health 2007, 39:74-81.

33. Cahn MA, Harvey SM, Town MA: American Indian and Alaska Native Men's Use of Sexual Health Services, 2006-2010. Perspect Sex Reprod Health 2017 Sep;49(3):181-189 doi: 101363/psrh12034 Epub 2017 Jul 312017.

34. Okigbo CC, Speizer IS, Corroon M, Gueye A: Exposure to family planning messages and modern contraceptive use among men in urban Kenya, Nigeria, and Senegal: a cross-sectional study. Reprod Health $2015 \mathrm{Jul}$ 22;12(1):63 doi: 101186/s12978-015-0056-1.

\section{Tables}


Table 1. Demographic characteristics of study participants.

\begin{tabular}{lcc}
\hline Variable & Number & Percentage \\
\hline Age (years) & & \\
\hline $18-29$ & 6 & $31.5 \%$ \\
\hline $30-39$ & 6 & $31.5 \%$ \\
\hline $40-49$ & 4 & $21 \%$ \\
\hline $50-59$ & 3 & $16 \%$ \\
\hline Education & & \\
\hline Illiterate & 2 & $10 \%$ \\
\hline Primary/Guidance school & 3 & $16 \%$ \\
\hline High school/ Diploma & 4 & $21 \%$ \\
\hline Higher Education & 10 & $52 \%$ \\
\hline Marital status & & \\
\hline Single & 9 & $48 \%$ \\
\hline Married & 10 & $52 \%$ \\
\hline Income & & \\
\hline Less than 500 USD & 2 & $10 \%$ \\
\hline $500-1000$ USD & 8 & $42 \%$ \\
\hline More than 1000 USD & 9 & $48 \%$ \\
\hline Having children & 9 & \\
\hline Yes & 10 & \\
\hline No & & \\
\hline Total & $900 \%$ \\
\hline & & \\
\hline
\end{tabular}


Table 2. Concepts, categories, and sub-categories of sexual and reproductive health.

\begin{tabular}{|c|c|c|}
\hline & Category & Sub-category \\
\hline \multirow{9}{*}{ Needs } & \multirow[t]{2}{*}{$\begin{array}{l}\text { Access to sexual and reproductive health } \\
\text { services }\end{array}$} & $\begin{array}{l}\text { Sexual and reproductive health service } \\
\text { delivery centers }\end{array}$ \\
\hline & & Supportive environment \\
\hline & \multirow[t]{3}{*}{ Awareness } & Sexual issues \\
\hline & & STIs/ HIV/AIDS \\
\hline & & Cancers and Infertility \\
\hline & \multirow[t]{4}{*}{ High-quality and safe sex } & Sexual pleasure \\
\hline & & Sexual satisfaction \\
\hline & & Safety of sex \\
\hline & & Sexual function \\
\hline \multirow[t]{10}{*}{ Responsibilities } & \multirow[t]{2}{*}{ Health-seeking behaviors } & Regular check ups \\
\hline & & Fear and hiding problems \\
\hline & \multirow[t]{3}{*}{ Sexual skills } & Sexual negotiation \\
\hline & & Interactive and respectable sex practice \\
\hline & & Sexually protective behavior \\
\hline & \multirow[t]{3}{*}{ Childbearing responsibilities } & Financing and providing children's welfare \\
\hline & & Parents' emotional maturity and skill \\
\hline & & Family planning \\
\hline & \multirow[t]{2}{*}{ Ethical commitment } & Marital and Extramarital relationships \\
\hline & & Child upbringing \\
\hline
\end{tabular}

\begin{tabular}{lll} 
Social norms & Gender role attitudes & Fertility and infertility \\
\cline { 2 - 2 } & Changing marriage rules & Sexuality \\
\cline { 2 - 3 } & White marriage \\
\hline
\end{tabular}

